\title{
Immediate Postoperative Parenteral Anticoagulant in the Patients with Mesenteric Infarction After Intestine Resection - A Retrospective Cohort Research in a Single Institute
}

Hsiao-Tien Liu ( $\square$ langhsky@vghtc.gov.tw)

Taichung Veterans General Hospital

Chia-Yu Lai

Taichung Veterans General Hospital

Jian-Jhou Liao

Taichung Veterans General Hospital

Yi-Ju Chen

Taichung Veterans General Hospital

Shao-Bin Cheng

Taichung Veterans General Hospital

Cheng-Chung Wu

Taichung Veterans General Hospital

\section{Research Article}

Keywords: mesenteric infarction, parenteral anticoagulant, intestine resection.

Posted Date: December 1st, 2021

DOI: https://doi.org/10.21203/rs.3.rs-1042318/v1

License: (c) (1) This work is licensed under a Creative Commons Attribution 4.0 International License.

Read Full License 


\section{Abstract}

Background: Bowel gangrene represents a major fatal event in acute mesenteric infarction. Intestinal resection is inevitable in patients with peritonitis and bowel gangrene. This retrospective study aimed to elucidate the benefit of postoperative parenteral anticoagulant in patients with intestinal resection.

Methods: Patients with acute mesenteric infarction and bowel gangrene were recruited retrospectively between January 2007 and December 2019. All patients underwent bowel resection. They were categorized into two groups: patients without immediate enoxaparin (group A) and those with immediate enoxaparin (group B). Both 30-day and 90-day mortalities were analyzed.

Results: A total of 85 patients were included, with 29 patients in group A and 56 patients in group B. Patients in group B had both lower 30-day mortality (16.1\%) and 90-day mortality (37.5\%), compared to patients in group A (30-day mortality: $51.7 \%, p=0.001$; 90-day mortality: $65.5 \%, p=0.021$ ). In the 30-day mortality multivariate analysis, patients in group B had a better outcome (odds ratio $=0.087,95 \%$ confidence interval between 0.017 and $0.446, p=0.003$ ). In the 90 -day mortality multivariate analysis, patients in group $B$ also had a better outcome (odds ratio $=0.252,95 \%$ confidence interval between 0.065 and $0.983, p=0.047)$.

Conclusion: Immediate postoperative parenteral anticoagulant improves short-term prognosis in patients with acute mesenteric infarction and intestinal resection.

Trial registration: This research was retrospectively approved by Institutional Review Board (IRB) I\&Il of Taichung Veterans General Hospital (TCVGH-IRB No.CE21256B) on July $28^{\text {th }}, 2021$. Informed consent waiver was also approved by IRB I\&II of Taichung Veterans General Hospital. Declaration of Helsinki and ICH-GCP guidelines were followed during this study.

\section{Background}

Mesenteric ischemia is characterized by insufficient splanchnic perfusion leading to failure of the intestinal metabolic demands, eventually resulting in ischemic tissue injury [1]. Mesenteric ischemia is divided into acute and chronic patterns. There are four different etiological forms of acute mesenteric ischemia (AMI), as follows: arterial embolism (EAMI), arterial thrombosis (TAMI), non-occlusive mesenteric ischemia (NOMI), and venous thrombosis (VAMI) [2]. The incidence of AMI is estimated to be about 1:1,000 of acute hospital admissions in Europe and the USA [3]. This figure accounts for about 1:10,000 in Japan, where the incidence of vascular disease is also lower [4]. In the 1990s, the mortality rate was quite high with an average of $71 \%$, ranging between $59 \%$ and $93 \%$. Delayed diagnosis and the existence of the intestinal gangrene were also shown to be poor prognostic factors [5].

In the past two decades, early diagnosis with successful revascularization is able to improve survival, with 30-day mortality rates between $6.9 \%$ and $29.6 \%[6,7,8]$. However, the survival rate remains poor in patients with AMI who had intestinal gangrene and resection treatment, with mortality rates between $27 \%$ 
and $59 \%[9,10,11,12]$. Immediate anticoagulation for a patient with VAMI is indicated whether the patient requires surgical intervention or not. Heparinization is indicated in patients with EAMI, TAMI, and NOMI, but period and dosage are controversial [5]. In patients with arterial occlusion, low-molecularweight heparins (LMWHs) are suggested during the critical postoperative period after intestine resection [13]. To our knowledge, there are few studies on postoperative anticoagulation in patients with AMI. We conducted a retrospective study to elucidate the influence of postoperative anticoagulant on survival in patients with $\mathrm{AMI}$ after emergent intestinal resection.

\section{Methods}

Between January 2007 and December 2019, we retrospectively recruited patients with AMI and intestinal gangrene. Patients who experienced intestinal gangrene and resection were included. The preoperative diagnosis of AMI was determined by contrast computed tomography (CT). The gangrene of bowel was confirmed by pathological finding. Patients without intestinal resection, intestinal gangrene, or preoperative contrast CT were all excluded. Patients with isolated ischemic colitis were also excluded. Patients with intestinal gangrene resulting from adhesion, abdominal wall hernia, internal herniation, or malignancy were all excluded.

Background factors were collected, including age, gender, type 2 diabetes mellitus, end-stage renal disease with dialysis (both hemodialysis and peritoneal dialysis), and recent major cardiovascular procedure (within 3 months). The major cardiovascular procedures included coronary arterial bypass, coronary arterial angioplasty/stent, cardiac valvular surgery, aortic surgery, and peripheral arterial surgery. Preoperative blood cell counts included white cell counts, differential counts, platelet counts, neutrophilto-lymphocyte ratio (NLR) [14], and hemoglobin level. Preoperative blood biochemistry included serum levels of albumin, alanine aminotransferase (ALT), bilirubin, and creatinine. Coagulation test included prothrombin time (PT) and was expressed by international normalized ratio (INR). Preoperative shock status was defined as requirement of vasopressors or inotropes. The types of AMI were determined by preoperative contrast CT.

Patients underwent emergent laparotomy under general anesthesia. Operative factors included combined colon resection and blood transfusion. Both postoperative anticoagulant and antiplatelet agents were recorded. Postoperative mortality was defined as death after intestinal resection. The periods between intestinal resection and death were measured. Both 30-day and 90-day mortalities were analyzed.

We used IBM SPSS version 22.0 for the statistical analysis. The continuous data were presented as the median with range. Categorical variables were compared by Pearson's chi-square or Fisher's exact as appropriate. Continuous variables were compared by Mann-Whitney $U$ test (Nonparametric method). The multivariate analysis for risk factors of mortality was conducted using a logistic regression model. The significance was defined as $p<0.05$.

\section{Results}


We collected 95 patients who had AMI and intestinal resection in our single institute between January 2007 and December 2019. Ten of the patients did not have a CT scan before surgery and thus a total of 85 patients were included in the analysis. The median age was 77 years with a range between 23 and 95 years. There were 35 females and 50 males. The numbers of patients with EAMI, TAMI, NOMI, and VAMI were $18,27,35$, and 5 , respectively. The overall 30 -day and 90 -day mortalities were $28.2 \%$ and $47.1 \%$, respectively. Nineteen patients had recent major cardiovascular procedures. Six patients underwent coronary arterial bypass graft, 5 patients had cardiac valvular surgery, 5 patients had aortic surgery, 2 patients had peripheral arterial surgery, and 1 patient had percutaneous coronary angioplasty with stent.

Of the 85 patients, 40 patients died within 90 days. Definite sepsis (positive bacteria cultures and systemic inflammatory response syndrome) occurred in 21 patients. Among the 19 patients who died of non-sepsis insult, hepatic failure, noted in 12 patients, was the most common organ failure at death, followed by renal failure and then heart and respiratory failure (Table 1).

The postoperative anticoagulants and antiplatelets included different agents. In our institute, the most commonly used parenteral anticoagulant agent is enoxaparin. We categorized patients into two groups. The patients who did not have immediate postoperative parenteral anticoagulants were categorized into group $A$ and those who had immediate postoperative parenteral anticoagulants were included in group $B$. There were 29 and 56 patients in groups A and B, respectively. In group B, 50 patients had immediate postoperative subcutaneous enoxaparin, 5 patients had intravenous heparin for one day and then subcutaneous enoxaparin was administered, and 1 patient had intravenous heparin for one day only. The daily dosages of enoxaparin were between $20 \mathrm{mg}$ and $120 \mathrm{mg}$, with one injection given every 24 hours or two injections every 12 hours. When enteral medication became available, 4 patients had oral antiplatelets in group A. Eighteen patients had oral antiplatelets, 12 patients had oral anticoagulants, and 4 patients had both in group $B$.

A comparison of demographics and other characteristics between group A and B is presented in Table 2 . There were no significant differences in background factors between the two groups. The normal range of white blood cell was defined as between 4,000 and 12,000 /uL [15]. The white blood cell distribution, including total counts and existence of immature neutrophils, revealed significant differences between the two groups. Patients had lower levels of serum albumin and hemoglobin, and higher levels of serum creatinine in group A. More patients underwent combined colon resections in group $B$. There were both significantly lower 30-day and 90-day mortality rates in group B.

The risk factors of 30-day mortality were analyzed by univariate and multivariate methods and the results are shown in Table 3. Patients had a lower mortality rate in group $B(p=0.001)$. Recent cardiovascular procedures, preoperative shock status, thrombocytopenia (platelets $<100,000 / \mathrm{uL}$ ), hypoalbuminemia (serum albumin $<2.8 \mathrm{~g} / \mathrm{dL}$ ), elevated serum ALT ( $\geq 100 \mathrm{U} / \mathrm{L})$, and elevated serum creatinine $(\geq 2.0$ $\mathrm{mg} / \mathrm{dL}$ ) had significant impacts on 30-day mortality. We included factors that were $p<0.1$ in the multivariate analysis. Thrombocytopenia and elevated serum ALT were significant unfavorable factors. 
Patients in group B still had a better outcome than those in group A (odds ratio $=0.087,95 \%$ confidence interval between 0.017 and $0.446, p=0.003$ ).

Table 4 shows the analysis of risk factors of the 90-day mortality, both by univariate and multivariate methods. There was a lower mortality rate in group $B(p=0.021)$. The presence of immature neutrophils, preoperative shock status, combined colon resection, prolonged INR of PT $(>1.7)$, hypoalbuminemia (serum albumin $<2.8 \mathrm{~g} / \mathrm{dL}$ ), elevated serum ALT ( $\geq 100 \mathrm{U} / \mathrm{L}$ ), hyperbilirubinemia (serum bilirubin $\geq 2.0$ $\mathrm{mg} / \mathrm{dL}$ ), and elevated serum creatinine ( $\geq 2.0 \mathrm{mg} / \mathrm{dL}$ ) were significant risk factors of 90-day mortality. Factors with $p<0.1$ were calculated by multivariate analysis. Patients in group B still had a better outcome than those in group $A$ (odds ratio $=0.252,95 \%$ confidence interval between 0.065 and $0.983, p=$ 0.047).

\section{Discussion}

Intestinal gangrene is a severe event with a poor prognosis in patients with AMI [5]. Early diagnosis and intervention, especially within 12 hours, can reduce the mortality and preserve more viable intestine [16, 17]. However, when intestinal gangrene and peritonitis develop, immediate laparotomy must be performed to achieve curative treatment $[18,19]$. Enteral medication is always unavailable in the short critical period after intestine resection. LMWHs are suggested in all patients undergoing revascularization and/or intestine resection during the critical postoperative period [13]. In the current study, patients with postoperative parenteral anticoagulants, especially enoxaparin, had a lower mortality rate after intestinal resection, in spite of the absence of revascularization.

LMWHs are glycosaminoglycans consisting of chains of alternating residues of D-glucosamine and an uronic acid, either gluconic acid or iduronic acid [20]. LMWHs are fragments of unfractionated heparin produced by controlled enzymatic or chemical depolymerization processes that yield chains with a mean molecular weight between 4,000 and 6,000, and the mean molecular weight of enoxaparin is 4,200 [21]. Compared to heparin, LMWHs have more effective anti-Xa activity than anti-lla activity, a more predictable anticoagulant response, and a lower incidence of heparin induced thrombocytopenia [22]. Enoxaparin also decreases platelet activity through COX1 in patients with coronary artery disease [23]. In patients with hemodialysis, enoxaparin reduces platelet reaction by decreasing the ability of platelets to bind fibrinogen (glycoprotein Ilb/llla activation) and express P-selectin in response to adenosine diphosphate [24]. Clinically, enoxaparin can be used in patients with atrial fibrillation, pulmonary embolism, and deep vein thrombosis by its antithrombotic activity $[25,26]$. Enoxaparin can also be used in patients with unstable angina and non ST-elevation myocardial infarction during the period of percutaneous coronary intervention [27]. The main effect of enoxaparin is its direct antithrombotic activity, as well as indirect antiplatelet activity.

In patients with sepsis, hypercoagulation is induced by impairing both protein $\mathrm{C}$ and antithrombin systems [28]. Inappropriate accumulation and activity of platelets contribute to hyperinflammation and microthrombosis [29]. Severe sepsis, classically associated with gram negative bacteria infection, 
eventually leads to disseminated intravascular coagulation and multiple organ dysfunction syndrome [30]. In patients with mesenteric ischemia, both platelet-endothelial cell interaction and platelet-leukocyte adhesion also contribute to inflammation during intestine ischemia/reperfusion injury [31]. LMWHs may treat or prevent severe hypercoagulation in patients with sepsis [32,33]. In critically ill, non-bleeding patients with disseminated intravascular coagulation, prophylaxis for venous thromboembolism with prophylactic doses of heparin or LMWHs is recommended [34].

In the present study, all patients had intestinal gangrene and resection treatment. This implies that all patients may have intestinal microorganism overgrowth, although not all patients had positive bacterial culture from ascites or blood. Sixty-two patients $(72.9 \%)$ had abnormal WBC count or immature WBC before surgery (data not shown). Seventy-four patients (87.1\%) had 2 or more points of sepsis-related organ failure score (SOFA score [35], data not shown). Most of our patients experienced both AMI and sepsis. Immediate postoperative anticoagulants may prevent recurrent vascular thrombosis/embolism, sepsis-induced hypercoagulation, and inappropriate platelet activity inducing ischemia/reperfusion intestinal injury.

After a short period of critical illness, enteral antiplatelet or anticoagulant is suggested to avoid recurrent ischemia events. Patients with diabetes or hypertension are at high risk of coronary thrombosis and should be treated by antiplatelet therapy [2]. Patients with atrial fibrillation, accounting for one-third of EAMI, should be treated using an anticoagulant $[36,37]$. In our study, 34 patients $(60.7 \%)$ had enteral antiplatelet or anticoagulant in group B. The antiplatelets included clopidogrel and aspirin, and the anticoagulants included warfarin and rivaroxaban.

The risk factors of mortality include advanced age (more than 70 years), diabetes mellitus, use of digoxin and antiplatelet, delayed surgery, existence of shock status, metabolic acidosis, hypoalbuminemia, recent myocardial infarction, previous cardiac surgery, and colon involvement $[9,11,38,39]$. In-hospital mortality, 30-day mortality, and 90-day mortality were used for analysis in previous studies. In-hospital mortality is too erratic to represent an accurate postoperative interval. For example, a patient who survived at first admission and died within 90 days of postoperative period would be categorized in the survival group. We calculated both 30-day and 90-day mortality. In the present study, preoperative shock status, hypoalbuminemia, elevated ALT, and elevated creatinine represent significant risk factors for both 30-day and 90-day mortalities by univariate analysis. Use of postoperative parenteral anticoagulants revealed significant advantages for both 30-day and 90-day mortalities by multivariate analysis.

A major limitation in this study was the dosage of anticoagulant. Due to the retrospective method employed in this study, dosage control was not achievable. The doses chosen by the physician might be influenced by patients' serum creatinine levels, blood platelet counts, INR of PT, and perioperative bleeding events. Two patients with postoperative severe bleeding events, intracranial hemorrhage and gastrointestinal bleeding, were in group A. Another study limitation was the periods of parenteral anticoagulant administration and shifting to enteral antiplatelet/anticoagulant. The periods of enoxaparin use were between 1 and 32 days. In group B, 8 patients had a short period of use (less than 3 
days) and 5 of them were due to mortality within 3 days after surgery. It was not possible to reach a definite conclusion regarding the optimal beneficial dosage and period based on our research, and thus further study is necessary to shed light on this issue.

\section{Conclusion}

Immediate postoperative parenteral anticoagulants can benefit the short-term prognosis in patients with acute mesenteric ischemia and intestinal gangrene after resection treatment. We suggest that subcutaneous enoxaparin is beneficial in patients during the critical postoperative period.

\section{Abbreviations}

AMI

acute mesenteric ischemia.

EAMI

arterial embolism.

TAMI

arterial thrombosis.

NOMI

non-occlusive mesenteric ischemia.

VAMI

venous thrombosis.

LMWHs

low-molecular-weight heparins.

CT

computed tomography.

NLR

neutrophil-to-lymphocyte ratio.

ALT

alanine aminotransferase.

PT

prothrombin time.

INR

international normalized ratio.

\section{Declarations}

\section{Ethics approval and consent to participate}

This research was retrospectively approved by Institutional Review Board (IRB) I\&Il of Taichung Veterans General Hospital (TCVGH-IRB No.CE21256B) on July $28^{\text {th }}, 2021$. Informed consent waiver was also 
approved by IRB I\&II of Taichung Veterans General Hospital. Declaration of Helsinki and ICH-GCP guidelines were followed during this study.

\section{Availability of data and materials}

The data generated and analysed during the current study are not publicly available because the Taiwan (R.O.C.) government legally restricts by Personal Data Protection Act and Human Subjects Research Act. Data however are available from the corresponding author with de-linkage and deidentification on reasonable request.

\section{Consent for publication}

Not applicable.

\section{Competing interests}

All authors declared no conflict of interest.

\section{Funding}

Taichung Veterans General Hospital (TCVGH-1114601A).

\section{Author contribution}

Cheng-Chung $\mathrm{Wu}$, Shao-Bin Cheng , and Hsiao-Tien Liu conducted the study design. Jian-Jhou Liao and Yi-Ju Chen collected and investigated data. Formal analysis was performed by Hsiao-Tien Liu. Chia-Yu Lai and Hsiao-Tien Liu wrote the original draft. Hsiao-Tien Liu performed the final review and editing of the manuscript.

\section{Acknowledgement}

We thank Ms. Fen-Ling Kuo, the paramedical staff of surgery department of Taichung Veterans General Hospital, for helping data storage. We also thank Mr. Peter Wilds, the language editor at Taichung Veterans General Hospital, for linguistic consultant.

\section{References}

1. Ahmed R, Malas M. Chapter 354: Mesenteric vascular insufficiency. In: Kasper D, Fauci A, Hauser S, Longo D, Jameson J, Loscalzo J, editors. Harrison's Principles of Internal Medicine, Nineteenth Edition. McGraw-Hill; 2014. eBook ISBN: 978-0-07-1802161.

2. Tilsed JV, Casamassima A, Kurihara H, Mariani D, Martinez I, Pereira J, et al. ESTES guidelines: acute mesenteric ischaemia. Eur J Trauma Emerg Surg. 2016;42:253-70.

3. Stoney RJ, Cunningham CG. Acute mesenteric ischemia. Surgery. 1993;114:489-90. 
4. Haga Y, Odo M, Homma M, Komiya K, Takeda K, Koike S, et al. New prediction rule for mortality in acute mesenteric ischemia. Digestion. 2009;80:104-11.

5. Brandt LJ, Boley SJ. AGA technical review on intestinal ischemia. Gastroenterology. 2000;118:95468.

6. Duran M, Pohl E, Grabitz K, Schelzig H, Sagban TA, Simon F. The importance of open emergency surgery in the treatment of acute mesenteric ischemia. World J Emerg Surg. 2015;10:45.

7. Roussel A, Castier Y, Nuzzo A, Pellenc Q, Sibert A, Panis Y, et al. Revascularization of acute mesenteric ischemia after creation of a dedicated multidisciplinary center. J Vasc Surg. 2015;62:1251-6.

8. Ryer EJ, Kalra M, Oderich GS, Duncan AA, Gloviczki P, Cha S, et al. Revascularization for acute mesenteric ischemia. J Vasc Surg. 2012;55:1682-9.

9. Alhan E, Usta A, Çekiç A, Saglam K, Türkyılmaz S, Cinel A. A study on 107 patients with acute mesenteric ischemia over 30 years. Int J Surg. 2012;10:510-3.

10. Dahlke MH, Asshoff L, Popp FC, Feuerbach S, Lang SA, Renner P, et al. Mesenteric ischemia--outcome after surgical therapy in 83 patients. Dig Surg. 2008;25:213-9.

11. Gupta PK, Natarajan B, Gupta H, Fang X, Fitzgibbons RJ Jr. Morbidity and mortality after bowel resection for acute mesenteric ischemia. Surgery. 2011;150:779-87.

12. Yıldırım D, Hut A, Tatar C, Dönmez T, Akıncı M, Toptaş M. Prognostic factors in patients with acute mesenteric ischemia. Turk J Surg. 2017;33:104-9.

13. Acosta S. Surgical management of peritonitis secondary to acute superior mesenteric artery occlusion. World J Gastroenterol. 2014;20:9936-41.

14. Liu X, Shen Y, Wang H, Ge Q, Fei A, Pan S. Prognostic Significance of Neutrophil-to-Lymphocyte Ratio in Patients with Sepsis: A Prospective Observational Study. Mediators Inflamm. 2016;2016:8191254.

15. Nierhaus A, Klatte S, Linssen J, Eismann NM, Wichmann D, Hedke J, et al. Revisiting the white blood cell count: immature granulocytes count as a diagnostic marker to discriminate between SIRS and sepsis--a prospective, observational study. BMC Immunol. 2013;14:8.

16. Eltarawy IG, Etman YM, Zenati M, Simmons RL, Rosengart MR. Acute mesenteric ischemia: the importance of early surgical consultation. Am Surg. 2009;75:212-9.

17. Kougias P, Lau D, El Sayed HF, Zhou W, Huynh TT, Lin PH. Determinants of mortality and treatment outcome following surgical interventions for acute mesenteric ischemia. J Vasc Surg. 2007;46:46774.

18. Bobadilla JL. Mesenteric ischemia. Surg Clin North Am. 2013;93:925-40.

19. Klar E, Rahmanian PB, Bücker A, Hauenstein K, Jauch KW, Luther B. Acute mesenteric ischemia: a vascular emergency. Dtsch Arztebl Int. 2012;109:249-56.

20. Hirsh J, Levine MN. Low molecular weight heparin. Blood. 1992;79:1-17.

21. Weitz Jl. Low-molecular-weight heparins. N Engl J Med. 1997;337:688-98. 
22. Hirsh J, Bauer KA, Donati MB, Gould M, Samama MM, Weitz JI. Parenteral anticoagulants: American College of Chest Physicians Evidence-Based Clinical Practice Guidelines (8th Edition). Chest. 2008;133 Suppl 6:141S-159S.

23. Arantes FBB, Menezes FR, Franci A, Barbosa CJDG, Dalçoquio TF, Nakashima CAK, et al. Influence of Direct Thrombin Inhibitor and Low Molecular Weight Heparin on Platelet Function in Patients with Coronary Artery Disease: A Prospective Interventional Trial. Adv Ther. 2020;37:420-30.

24. Aggarwal A, Whitaker DA, Rimmer JM, Solomon RJ, Gennari FJ, Sobel BE, et al. Attenuation of platelet reactivity by enoxaparin compared with unfractionated heparin in patients undergoing haemodialysis. Nephrol Dial Transplant. 2004;19:1559-63.

25. Hacobian M, Shetty R, Niles CM, Gerhard-Herman M, Vallurupalli N, Baroletti S, et al. Once daily enoxaparin for outpatient treatment of acute venous thromboembolism: a case-control study. Clin Appl Thromb Hemost. 2010;16:21-5.

26. Murray RD, Shah A, Jasper SE, Goodman A, Deitcher SR, Katz WE, et al. Transesophageal echocardiography guided enoxaparin antithrombotic strategy for cardioversion of atrial fibrillation: the ACUTE II pilot study. Am Heart J. 2000;139:E1-7.

27. Levine GN, Bates ER, Blankenship JC, Bailey SR, Bittl JA, Cercek B, et al. 2011 ACCF/AHA/SCAI Guideline for Percutaneous Coronary Intervention: a report of the American College of Cardiology Foundation/American Heart Association Task Force on Practice Guidelines and the Society for Cardiovascular Angiography and Interventions. Circulation. 2011;124:e574-651.

28. Levi M. The coagulant response in sepsis. Clin Chest Med. 2008;29:627-42.

29. de Stoppelaar SF, van 't Veer C, van der Poll T. The role of platelets in sepsis. Thromb Haemost. 2014;112:666-77.

30. Semeraro N, Ammollo CT, Semeraro F, Colucci M. Sepsis, thrombosis and organ dysfunction. Thromb Res. 2012;129:290-95.

31. Vollmar B, Menger MD. Intestinal ischemia/reperfusion: microcirculatory pathology and functional consequences. Langenbecks Arch Surg. 2011;396:13-29.

32. Levi M, Levy M, Williams MD, Douglas I, Artigas A, Antonelli M, et al; Xigris and Prophylactic HepaRin Evaluation in Severe Sepsis (XPRESS) Study Group. Prophylactic heparin in patients with severe sepsis treated with drotrecogin alfa (activated). Am J Respir Crit Care Med. 2007;176:483-90.

33. Sakuragawa N, Hasegawa H, Maki M, Nakagawa M, Nakashima M. Clinical evaluation of lowmolecular-weight heparin (FR-860) on disseminated intravascular coagulation (DIC)-a multicenter co-operative double-blind trial in comparison with heparin. Thromb Res. 1993;72:475-500.

34. Levi M, Toh CH, Thachil J, Watson HG. Guidelines for the diagnosis and management of disseminated intravascular coagulation. British Committee for Standards in Haematology. Br J Haematol. 2009;145:24-33.

35. Singer M, Deutschman CS, Seymour CW, Shankar-Hari M, Annane D, Bauer M, et al. The Third International Consensus Definitions for Sepsis and Septic Shock (Sepsis-3). JAMA. 2016;315:80110. 
36. Edwards MS, Cherr GS, Craven TE, Olsen AW, Plonk GW, Geary RL, et al. Acute occlusive mesenteric ischemia: surgical management and outcomes. Ann Vasc Surg. 2003;17:72-9.

37. Klempnauer J, Grothues F, Bektas H, Pichlmayr R. Long-term results after surgery for acute mesenteric ischemia. Surgery. 1997;121:239-43.

38. Unalp HR, Atahan K, Kamer E, Yaşa H, Tarcan E, Onal MA. Prognostic factors for hospital mortality in patients with acute mesenteric ischemia who undergo intestinal resection due to necrosis. Ulus Travma Acil Cerrahi Derg. 2010;16:63-70.

39. Wadman M, Syk I, Elmståhl S. Survival after operations for ischaemic bowel disease. Eur J Surg. 2000;166(11):872-877.

\section{Tables}

Table 1, cause of death

\begin{tabular}{|lll|}
\hline & & Patient number \\
\hline Sepsis & & 21 \\
\hline Non-sepsis & 19 \\
\hline Organ failure in non-sepsis & Liver & 17 \\
\hline & Kidney & 7 \\
\hline & Heart & 4 \\
\hline & Lung & 4 \\
\hline
\end{tabular}

Table 2, demographic characteristics of group A and B 


$$
\text { Group A (n=29) }
$$

Group B $(n=56)$

$\mathrm{P}$

value

Background factors

\begin{tabular}{|c|c|c|c|}
\hline Age (year) ${ }^{a}$ & $78(41-95)$ & $75(23-92)$ & 0.363 \\
\hline Gender (female/male) & $14 / 15$ & $21 / 35$ & 0.362 \\
\hline Type (EAMI/TAMI/NOMI/VAMI) & $4 / 10 / 15 / 0$ & $14 / 17 / 20 / 5$ & 0.171 \\
\hline $\begin{array}{l}\text { Recent cardiovascular procedure } \\
\text { (n) }\end{array}$ & 7 & 12 & 0.789 \\
\hline Diabetes mellitus ( $n$ ) & 13 & 20 & 0.484 \\
\hline Dialysis (n) & 9 & 9 & 0.161 \\
\hline
\end{tabular}

Preoperative factors

WBC count(/uL)

$15,400(3,250-37,700)$

$11,685(890-28,800)$

0.031

WBC count out of normal range ${ }^{c}$

20

28

0.111 (n)

Positive band form of WBC (n)

21

26

0.037

NLR (\%)

$12.7(2.7-98.0)$

$13.0(1.9-97.0)$

0.704

Platelet count (/uL) $139,000(14,000-$ $485,000)$

$145,500(21,000-$ 0.871 $341,000)$

INR of PT

Hemoglobin $(\mathrm{g} / \mathrm{dL})$

Serum albumin (g/dL)

Serum ALT (U/L)

Serum bilirubin $(\mathrm{mg} / \mathrm{dL})$

Serum creatinine $(\mathrm{mg} / \mathrm{dL})$

Shock status (n)

Surgical factors

Intraoperative red blood

transfusion (n)

Combined colon resection ( $n$ )

Prognosis

30-days mortality (n)

$\begin{array}{lll}1.17(0.91-8.77) & 1.13(0.88-3.50) & 0.226 \\ 10.3(6.1-14.8) & 11.9(6.0-16.6) & 0.012 \\ 2.5(1.2-4.5) & 3.1(1.5-4.5) & 0.002 \\ 28(7-3049) & 30(4-1332) & 0.714 \\ 0.8(0.2-6.4) & 0.9(0.3-9.5) & 0.451 \\ 3.7(0.9-12.0) & 2.5(0.40-12.1) & 0.047 \\ 14 & 15 & 0.057\end{array}$

2

4

22

0.024

7

0.712

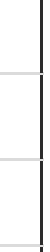



a. median (range).
b. experiencing major cardiovascular procedure within 90 days before intestine resection.
c. normal range of WBC: between 4,000 and 12,000 /uL.

EAMI: arterial embolism; TAMI: arterial thrombosis; NOMI: non-occlusive mesenteric ischemia; VAMI: venous thrombosis; WBC: white blood cell; NLR: neutrophil-to-lymphocyte ratio; INR: international normalized ratio; PT: prothrombin time; ALT: alanine aminotransferase;

Table 3, 30-day mortality analysis 


\begin{tabular}{|c|c|c|c|c|c|}
\hline & & $\begin{array}{l}\text { Univariate } \\
\text { analysis }\end{array}$ & & $\begin{array}{l}\text { Multivariate } \\
\text { analysis }\end{array}$ & \\
\hline & & $\begin{array}{l}\text { 30-days } \\
\text { mortality }\end{array}$ & $\begin{array}{l}P \\
\text { value }\end{array}$ & $\begin{array}{l}\text { Odds ratio (95\% } \\
\mathrm{Cl})\end{array}$ & $\begin{array}{l}\mathrm{P} \\
\text { value }\end{array}$ \\
\hline \multirow[t]{2}{*}{ Group } & A & $51.7 \%$ & 0.001 & Ref. & 0.003 \\
\hline & B & $16.1 \%$ & & $\begin{array}{l}0.087(0.017- \\
0.446)\end{array}$ & \\
\hline \multicolumn{6}{|l|}{ Background factors } \\
\hline \multirow[t]{2}{*}{ Age } & $<65$ year & $33.3 \%$ & 0.583 & & \\
\hline & $\geq 65$ year & $26.6 \%$ & & & \\
\hline \multirow[t]{2}{*}{ Gender } & Female & $31.4 \%$ & 0.630 & & \\
\hline & Male & $26.0 \%$ & & & \\
\hline \multirow[t]{4}{*}{ Type } & EAMI & $22.2 \%$ & 0.292 & & \\
\hline & TAMI & $25.9 \%$ & & & \\
\hline & NOMI & $37.1 \%$ & & & \\
\hline & VAMI & $0.0 \%$ & & & \\
\hline \multirow{2}{*}{$\begin{array}{l}\text { Recent cardiovascular } \\
\text { procedure }^{a}\end{array}$} & No & $21.2 \%$ & 0.018 & Ref. & 0.637 \\
\hline & Yes & $52.6 \%$ & & $\begin{array}{l}1.518(0.269- \\
8.566)\end{array}$ & \\
\hline \multirow[t]{2}{*}{ Diabetes mellitus } & No & $23.1 \%$ & 0.221 & & \\
\hline & Yes & $36.4 \%$ & & & \\
\hline \multirow[t]{2}{*}{ Dialysis } & No & $28.4 \%$ & 1.000 & & \\
\hline & Yes & $27.8 \%$ & & & \\
\hline \multicolumn{6}{|l|}{ Preoperative factors } \\
\hline \multirow{2}{*}{$\begin{array}{l}\text { WBC count out of normal } \\
\text { range }^{b}\end{array}$} & No & $24.3 \%$ & 0.628 & & \\
\hline & Yes & $31.3 \%$ & & & \\
\hline \multirow[t]{2}{*}{ Positive band form of WBC } & No & $18.4 \%$ & 0.092 & Ref. & 0.195 \\
\hline & Yes & $36.2 \%$ & & $\begin{array}{l}0.329(0.061- \\
1.766)\end{array}$ & \\
\hline NLR & $<23.8$ & $27.0 \%$ & 0.784 & & \\
\hline
\end{tabular}




\begin{tabular}{|c|c|c|c|c|c|}
\hline & $\geq 23.8$ & $31.8 \%$ & & & \\
\hline \multirow[t]{2}{*}{ Platelet count } & $\begin{array}{l}\geq 10100,000 \\
/ \mathrm{LL}\end{array}$ & $16.9 \%$ & 0.001 & Ref. & 0.045 \\
\hline & $\begin{array}{l}<100,000 \\
/ \mathrm{uL}\end{array}$ & $53.8 \%$ & & $\begin{array}{l}5.214(1.036- \\
26.247)\end{array}$ & \\
\hline \multirow[t]{2}{*}{ INR of PT } & $\leq 1.7$ & $24.3 \%$ & 0.067 & Ref. & 0.798 \\
\hline & $>1.7$ & $54.5 \%$ & & $\begin{array}{l}1.312(0.164- \\
10.525)\end{array}$ & \\
\hline \multirow[t]{2}{*}{ Hemoglobin } & $\geq 12 \mathrm{~g} / \mathrm{dL}$ & $24.2 \%$ & 0.624 & & \\
\hline & $<12 \mathrm{~g} / \mathrm{dL}$ & $30.8 \%$ & & & \\
\hline \multirow[t]{2}{*}{ Serum albumin } & $\geq 2.8 \mathrm{~g} / \mathrm{dL}$ & $16.7 \%$ & 0.008 & Ref. & 0.349 \\
\hline & $<2.8 \mathrm{~g} / \mathrm{dL}$ & $43.2 \%$ & & $\begin{array}{l}2.007(0.467- \\
8.624)\end{array}$ & \\
\hline \multirow[t]{2}{*}{ Serum ALT } & $<100 \mathrm{U} / \mathrm{L}$ & $17.9 \%$ & 0.000 & Ref. & 0.009 \\
\hline & $\geq 100 \mathrm{U} / \mathrm{L}$ & $66.7 \%$ & & $\begin{array}{l}13.564(1.910- \\
96.307)\end{array}$ & \\
\hline \multirow[t]{2}{*}{ Serum bilirubin } & $\begin{array}{l}<2.0 \\
\mathrm{mg} / \mathrm{dL}\end{array}$ & $24.2 \%$ & 0.153 & & \\
\hline & $\begin{array}{l}\geq 2.0 \\
\mathrm{mg} / \mathrm{dL}\end{array}$ & $42.1 \%$ & & & \\
\hline \multirow[t]{2}{*}{ Serum creatinine } & $\begin{array}{l}<2.0 \\
\mathrm{mg} / \mathrm{dL}\end{array}$ & $11.1 \%$ & 0.020 & Ref. & 0.549 \\
\hline & $\begin{array}{l}\geq 2.0 \\
\mathrm{mg} / \mathrm{dL}\end{array}$ & $36.2 \%$ & & $\begin{array}{l}1.760(0.277- \\
11.180)\end{array}$ & \\
\hline \multirow[t]{2}{*}{ Shock status } & No & $12.5 \%$ & 0.000 & Ref. & 0.093 \\
\hline & Yes & $58.6 \%$ & & $\begin{array}{l}3.461(0.812- \\
14.758)\end{array}$ & \\
\hline \multicolumn{6}{|l|}{ Surgical factors } \\
\hline \multirow{2}{*}{$\begin{array}{l}\text { Intraoperative red blood } \\
\text { transfusion }\end{array}$} & No & $28.9 \%$ & 1.000 & & \\
\hline & Yes & $22.2 \%$ & & & \\
\hline \multirow[t]{2}{*}{ Combined colon resection } & No & $25.4 \%$ & 0.438 & & \\
\hline & Yes & $34.6 \%$ & & & \\
\hline
\end{tabular}


a. experiencing major cardiovascular procedure within 90 days before intestine resection.

b: normal range of WBC: between 4,000 and 12,000 /uL.

EAMI: arterial embolism; TAMI: arterial thrombosis; NOMI: non-occlusive mesenteric ischemia; VAMI: venous thrombosis; WBC: white blood cell; NLR: neutrophil-to-lymphocyte ratio; INR: international normalized ratio; PT: prothrombin time; ALT: alanine aminotransferase; $\mathrm{Cl}$ : confidence interval; Ref.: reference.

Table 4, 90-day mortality analysis 


\begin{tabular}{|c|c|c|c|c|c|}
\hline & & $\begin{array}{l}\text { Univariate } \\
\text { analysis }\end{array}$ & & $\begin{array}{l}\text { Multivariate } \\
\text { analysis }\end{array}$ & \\
\hline & & $\begin{array}{l}\text { 90-days } \\
\text { mortality }\end{array}$ & $\begin{array}{l}\mathrm{P} \\
\text { value }\end{array}$ & $\begin{array}{l}\text { Odds ratio }(95 \% \\
\mathrm{Cl})\end{array}$ & $\begin{array}{l}\mathrm{P} \\
\text { value }\end{array}$ \\
\hline \multirow[t]{2}{*}{ Group } & $A$ & $65.5 \%$ & 0.021 & Ref. & 0.047 \\
\hline & $\mathrm{B}$ & $37.5 \%$ & & $\begin{array}{l}0.252(0.065- \\
0.983)\end{array}$ & \\
\hline \multicolumn{6}{|l|}{ Background factors } \\
\hline \multirow[t]{2}{*}{ Age } & $<65$ year & $42.9 \%$ & 0.802 & & \\
\hline & $\geq 65$ year & $48.4 \%$ & & & \\
\hline \multirow[t]{2}{*}{ Gender } & Female & $45.7 \%$ & 1.000 & & \\
\hline & Male & $48.0 \%$ & & & \\
\hline \multirow[t]{4}{*}{ Type } & EAMI & $50.0 \%$ & 0.150 & & \\
\hline & TAMI & $44.4 \%$ & & & \\
\hline & NOMI & $54.3 \%$ & & & \\
\hline & VAMI & $0.0 \%$ & & & \\
\hline \multirow{2}{*}{$\begin{array}{l}\text { Recent cardiovascular } \\
\text { procedure }^{a}\end{array}$} & No & $43.9 \%$ & 0.309 & & \\
\hline & Yes & $57.9 \%$ & & & \\
\hline \multirow[t]{2}{*}{ Diabetes mellitus } & No & $46.2 \%$ & 1.000 & & \\
\hline & Yes & $48.5 \%$ & & & \\
\hline \multirow[t]{2}{*}{ Dialysis } & No & $46.3 \%$ & 0.797 & & \\
\hline & Yes & $50.0 \%$ & & & \\
\hline \multicolumn{6}{|l|}{ Preoperative factors } \\
\hline \multirow{2}{*}{$\begin{array}{l}\text { WBC count out of normal } \\
\text { range }^{b}\end{array}$} & No & $37.8 \%$ & 0.189 & & \\
\hline & Yes & $54.2 \%$ & & & \\
\hline \multirow[t]{2}{*}{ Positive band form of WBC } & No & $31.6 \%$ & 0.016 & Ref. & 0.614 \\
\hline & Yes & $59.6 \%$ & & $\begin{array}{l}1.397(0.381- \\
5.117)\end{array}$ & \\
\hline \multirow[t]{2}{*}{ NLR } & $<23.8$ & $46.0 \%$ & 0.807 & & \\
\hline & $\geq 23.8$ & $50.0 \%$ & & & \\
\hline
\end{tabular}




\begin{tabular}{|c|c|c|c|c|c|}
\hline \multirow[t]{2}{*}{ Platelet count } & $\begin{array}{l}\geq 100,000 \\
/ \mathrm{uL}\end{array}$ & $40.7 \%$ & \multicolumn{2}{|l|}{0.100} & \\
\hline & $\begin{array}{l}<100,000 \\
/ \mathrm{uL}\end{array}$ & $61.5 \%$ & & & \\
\hline \multirow[t]{2}{*}{ INR of PT } & $\leq 1.7$ & $40.5 \%$ & 0.002 & Ref. & 0.127 \\
\hline & $>1.7$ & $90.9 \%$ & & $\begin{array}{l}6.888(0.576- \\
82.295)\end{array}$ & \\
\hline \multirow[t]{2}{*}{ Hemoglobin } & $\geq 12 \mathrm{~g} / \mathrm{dL}$ & $39.4 \%$ & 0.275 & & \\
\hline & $<12 \mathrm{~g} / \mathrm{dL}$ & $51.9 \%$ & & & \\
\hline \multirow[t]{2}{*}{ Serum albumin } & $\geq 2.8 \mathrm{~g} / \mathrm{dL}$ & $33.3 \%$ & 0.005 & Ref. & 0.064 \\
\hline & $<2.8 \mathrm{~g} / \mathrm{dL}$ & $64.9 \%$ & & $\begin{array}{l}3.007(0.940- \\
9.623)\end{array}$ & \\
\hline \multirow[t]{2}{*}{ Serum ALT } & $<100 \mathrm{U} / \mathrm{L}$ & $38.8 \%$ & 0.007 & Ref. & 0.276 \\
\hline & $\geq 100 \mathrm{U} / \mathrm{L}$ & $77.8 \%$ & & $\begin{array}{l}2.465(0.486- \\
12.495)\end{array}$ & \\
\hline \multirow[t]{2}{*}{ Serum bilirubin } & $\begin{array}{l}<2.0 \\
\mathrm{mg} / \mathrm{dL}\end{array}$ & $40.9 \%$ & 0.040 & Ref. & 0.161 \\
\hline & $\begin{array}{l}\geq 2.0 \\
\mathrm{mg} / \mathrm{dL}\end{array}$ & $68.4 \%$ & & $\begin{array}{l}2.765(0.666- \\
11.474)\end{array}$ & \\
\hline \multirow[t]{2}{*}{ Serum creatinine } & $\begin{array}{l}<2.0 \\
\mathrm{mg} / \mathrm{dL}\end{array}$ & $29.6 \%$ & 0.036 & Ref. & 0.989 \\
\hline & $\begin{array}{l}\geq 2.0 \\
\mathrm{mg} / \mathrm{dL}\end{array}$ & $55.2 \%$ & & $\begin{array}{l}0.991(0.258- \\
3.811)\end{array}$ & \\
\hline \multirow[t]{2}{*}{ Shock status } & No & $32.1 \%$ & 0.000 & Ref. & 0.080 \\
\hline & Yes & $75.9 \%$ & & $\begin{array}{l}3.106(0.873- \\
11.053)\end{array}$ & \\
\hline \multicolumn{6}{|l|}{ Surgical factors } \\
\hline \multirow{2}{*}{$\begin{array}{l}\text { Intraoperative red blood } \\
\text { transfusion }\end{array}$} & No & $46.1 \%$ & 0.729 & & \\
\hline & Yes & $55.6 \%$ & & & \\
\hline \multirow[t]{2}{*}{ Combined colon resection } & No & $39.0 \%$ & 0.034 & Ref. & 0.059 \\
\hline & Yes & $65.4 \%$ & & $\begin{array}{l}3.806(0.950- \\
15.248)\end{array}$ & \\
\hline
\end{tabular}

a. experiencing major cardiovascular procedure within 90 days before intestine resection. 
b. normal range of WBC: between 4,000 and 12,000 /uL.

EAMI: arterial embolism; TAMI: arterial thrombosis; NOMI: non-occlusive mesenteric ischemia; VAMI: venous thrombosis; WBC: white blood cell; NLR: neutrophil-to-lymphocyte ratio; INR: international normalized ratio; PT: prothrombin time; ALT: alanine aminotransferase; Cl: confidence interval; Ref.: reference. 